Evaluating Interdependence in Workgroups: A Network-Based Method

Daniel Griffin, Ajay V. Somaraju, Christopher Dishop, Richard P. DeShon

Michigan State University 


\begin{abstract}
Interdependence is a defining characteristic of groups and teams. However, a vast range of constructs and conceptualizations for interdependence have left researchers with a dizzying array of frameworks, metrics, and perspectives with which to evaluate interdependence. This situation leaves researchers no clear guidance on how to theorize about or measure interdependence, reducing the ability of researchers to accumulate knowledge. As a solution, we propose a network-based perspective of interdependence. We present a procedure for researchers to conceptualize interdependent relationships in a team in terms of a network and present a standardized index of interdependence. We show that our method is compatible with the many existing interdependence measures, indices, and constructs. Finally, we discuss how these approaches help advance the study of interdependence by moving interdependence research beyond individual-level, and centrality-based notions. We conclude with illustrative examples, and present various recommendations which will bring more clarity and unity to the study of interdependence.
\end{abstract}

Keywords: Interdependence, Social Networks, Teams, Groups, Multi-level Word count: 156 


\section{Evaluating Interdependence in Workgroups: A Network-Based Method}

Modern organizations are composed of teams and workgroups that are inherently interdependent (Kozlowski, 2015; Mathieu, Tannenbaum, Donsbach, \& Allinger, 2014; Hollenbeck, Beersma, \& Schouten, 2012; Lee, Koopman, Hollenbeck, Wang, \& Lanaj, 2015). Accordingly, many researchers have focused their investigations on interdependence and its relationship with key team processes (e.g., conflict, coordination; O’Brien, 1968; Marks, Mathieu, \& Zacarro, 2001) and outcomes (e.g., performance, helping behaviors, reward effectiveness; Courtright, Thurgood, Stewart, \& Pierotti, 2015; Wageman, 1995; Van der Vegt, Van de Vliert, \& Oosterhof, 2003; Barnes, et al., 2008). One challenge in this effort stems from the vast array of different conceptualizations and operationalizations for assessing interdependence (Courtright, et al., 2015). As a result, researchers often idiosyncratically apply methods to evaluate interdependence, leaving them with little means to connect disparate studies. To provide a solution for this problem, we present researchers with a unified approach to calculating interdependence. In doing so, we provide researchers with three crucial tools compatible with existing interdependence theory and metrics.

First, we provide a network-based method to represent interdependence. Our method coheres with any existing interdependence construct and connects the interdependence literature to network theory, thereby making available a vast array of useful dependence representations and characteristics (cf. Park, Grosser, Roebuck, \& Mathieu, 2020). Second, we demonstrate how researchers can flexibly use network-based representations to calculate interdependence metrics that are independent of scale or operationalization, which enables meaningful comparisons of interdependence estimates across studies and constructs (cf. Morris \& DeShon, 2002; Blanton \& Jaccard, 2006). Thus, our approach provides a consistent and standard process for evaluating and 
reporting various forms of interdependence, which facilitates comparisons of cross-study results and the accumulation of knowledge (e.g., meta-analyses). Furthermore, the network-based framework allows us to consider the inherently multilevel nature of interdependence, which is often been overlooked (Van Der Vegt \& Van De Vliert, 2002), and move beyond individuallevel centrality based approaches typical of interdependence research. Lastly, the use of network paradigms in the organizational literature is growing rapidly (Park, et al., 2020), and we therefore provide recommendations to facilitate the use of our network approach in the study of interdependence.

To organize our discussion, we first briefly review popular conceptualizations of interdependence and their respective methodological approaches to advance a generalizable definition of interdependence. Based upon our review, we present a unifying network approach to represent interdependence, and derive equations that can be used to calculate interdependence. We present an example in which we apply our equation, and close by discussing the implications of our index and some directions for future research.

\section{Overview of Interdependence Literature}

\section{Conceptualizations}

Interdependence has been heavily discussed in the organizational literature (Courtright, et al., 2015), and researchers have unsurprisingly conceptualized interdependence in a variety of ways. For instance, some researchers (e.g., Kiggundu, 1981) have conceptualized interdependence as the extent to which work done by a given role is required by other roles (i.e., initiated interdependence), and how much a given role requires work done by others (i.e., received interdependence). Other researchers conceptualize interdependence as the extent to 
which a role has both initiated and received interdependence (i.e., reciprocal interdependence; Pearce \& Gregerson, 1991).

Interdependence has also been described in terms of workflow and team process (Cataldo, Mockus, Roberts, \& Herbsleb, 2009), which can be further parsed into pooled and sequential interdependence (Victor \& Blackburn, 1987; Thompson, 1967). These forms of interdependence refer to the number of objective ways that one project relies on other tasks, how often two projects need to be completed concurrently, and the number of individuals involved with a single task or project (Cataldo, et al., 2009). Interdependence may also refer to the dependence on a specific resource (i.e., resource, input, or informational interdependence; Johnson et al., 1983; Rossi, 2008; Van Der Vegt, et al., 2003), role (i.e., role interdependence; Pennings, 1975; Tjosvold, 1986), task (i.e. task interdependence; O’Brien 1968), leader, or skill (horizontal-and vertical interdependence; Hollenbeck, et al., 2012). Finally, self-construal (Cross, Bacon, \& Morris, 2000; Niiya \& Crocker, 2019; Singelis, 1994), cognitive (Agnew et al., 1998; Davis \& Weigel, 2019), and goal (Johnson, Johnson, \& Anderson, 1983; Rossi, 2008; Somech, 2008; Tjosvold, Tang, \& West, 2004; Van Der Vegt et al., 2003) interdependence constructs have been developed, which refer to the unique aspects of perceived interdependence by an individual and their team in terms of tasks, goals, and cognition.

Recently, Courtright and colleagues (2015) have distilled many of these conceptualizations under a broader umbrella term of structural interdependence which reflects features of the team that connect members together and can be deliberately manipulated by team members and leadership (cf. Wageman, 1995). The authors further decompose structural interdependence into task and outcome interdependence. The former refers to the degree to which taskwork is designed so that members depend upon one another for access to resources 
and create workflows that require coordinated action", whereas the latter refers to "the degree to which the outcomes of taskwork are measured, rewarded, and communicated at the group level so as to emphasize collective outputs rather than individual contributions" (Courtright et al., 2015, p. 4).

\section{Measurement}

Interdependence can reflect many different ideas and has therefore been measured in many different ways. To demonstrate the diversity of interdependence measures we conducted a selective review. We searched Google Scholar using key words such as "interdependence” and "dependency" 1 " and performed forward- and backward citation searches within the relevant articles. Our results are summarized in Table 1 . We found that many measures assessed multiple forms of interdependence within the same survey and that many surveys assessed interdependence between different types of units (e.g., individual to individual, individual to team).

\section{INSERT TABLE 1 HERE}

Notably our review highlights that across conceptualizations, interdependence has often been measured by the connections between a focal unit (unit that is dependent) and a source unit [the unit(s) on which a focal unit is dependent], and how these connections affect the outcome of the focal unit. For instance, Kiggundu (1981) describes initiated interdependence as the degree to which work flows from a particular job to one or more other jobs, which can be measured

\footnotetext{
${ }^{1}$ We use the terms interdependence, dependency, interdependency interchangeably throughout this paper.
} 
through tasks (e.g., "How well one task is performed has a great effect on how well the other task can be performed"; Wong \& Campion, 1991), or the person or job (e.g., "Unless my job gets done, other jobs cannot be completed"; Morgeson \& Humphrey, 2006A). Here, the source unit is the respondent, the focal unit is the rest of the team, and the connections from the focal to the source unit represents the magnitude of interdependence. Similarly, Campion, Medsker, \& Higgs (1993A) assess goal interdependence (e.g., "My work goals come directly from the goals of my team"), Ashworth (2007) measures informational dependence ("I have to obtain information and advice from others on my team to complete my work"), and De Dreu et al (2001) measure reward dependence ("When one or more team members excel in their work, I benefit") through connections between focal (e.g., respondent) and source (e.g., team) units.

Observational indices have also sought to index interdependence through the connections between team members. For instance, O’Brien (1968) introduced a task by task matrix representation to quantify the amount of precedence relationships in a task network. In this approach, a low value of the index means that tasks can be completed irrespective of the status of other task, and performance on one does not depend on the performance or completion of another (cf. Wood, 1986; Oeser \& O’Brien, 1967). Lennox and colleagues (2007) presented a different approach to capture the complexity of task or activity configurations within a unit. Their index suggested that the amount of interdependence for a given unit (e.g., task, individual) grew concomitantly with the number of its dependent relationships. In sum, despite the varied conceptualizations and indices of interdependence, there exists clear overlap in the assessment of interdependence. Namely, most measures assess interdependence based on the connections between units, which makes them amenable to network representations.

\section{A Network Approach to Evaluating Interdependence}


Network representations have gained popularity in the organizational literature (Park, et al., 2020), applying widely to informal leadership positions (Carter, DeChurch, Braun, \& Contractor, 2015), instrumental and symbolic job features (Carter, et al., 2019), and workplace conflict (Park, Mathieu, \& Grosser, 2018). We propose that network perspectives offer similar utility with respect to interdependence for three reasons.

First, networks by design inherently express aspects of interconnectedness found among a group of units (e.g., individuals, goals, resources, etc.), which greatly coheres with the current approach to conceptualizing and measuring interdependence. Second, networks can flexibly represent any interdependent construct. Specifically, networks are formed through a pattern of edges (i.e. relationships) and nodes (units; Girvan \& Newman, 2002; Roberson \& Colquitt, 2005), wherein the nodes and edges can represent virtually any type of relationship or unit. Therefore, researchers can construe nodes to represent any type of focal or source unit and apply a network to virtually any form of interdependence. Finally, networks open the door for more nuanced considerations of interdependence related to evolving changes in taskflow and group membership (Mathieu \& Luciano, 2019). For instance, Crawford and LePine (2013) have recently advocated for a configural approach to operationalizing team constructs, that assess the patterns of interaction between team members, which could allow for better understanding of the complexities associated with team-related phenomena. In their review of the interdependence literature, Courtright and colleagues (2015) remarked that the configural approach may prove more useful than traditional compositional approaches (Kozlowski \& Klein, 2000) by enabling researches to more "directly measuring workflow or resource dependence patterns across group members to determine who in the team depends on whom to gain access to critical resources or 
accomplish work tasks, as opposed to capturing general shared perceptions of the extent to which team members' depend upon one another for task completion or resource access" (p. 16).

In short, as it currently stands, interdependence is an umbrella term capturing many constructs. This construct complexity is compounded by the many different ways that researchers can operationalize, measure, and evaluate interdependence within a group. Therefore, our approach offers this literature a common sequence of steps with which to study and describe interdependence, in an effort to stimulate cumulative knowledge and theory-building.

\section{Interdependence as a Network}

In order to understand dependency networks, we must start by briefly describing networks themselves (see Wasserman \& Faust, 1994). Networks are mathematically defined by a set of nodes (units), and a set of edges (relationships) that link any two nodes. Nodes can represent either focal or source units, and the directedness of the relationship indicates the directionality of dependence. Accordingly, the set of edges represents the set of all dyadic relationships between nodes. Notably, since the nodes can refer to any type of unit, the same dependency network can reflect vastly different aspects of a specific interdependence type.

For instance, a dependency network could be formed using a set of individuals (i.e. focal units) and the resources they require (i.e. source units). This resource dependency network may be helpful in identifying which individuals have heavier resource requirements as well as which resources are most important. On the other hand, the same network could be formed, wherein the nodes represent individuals who require the same resource. Now, both the focal unit and source unit represent individuals and the network representation would not include the specific resources they require. This representation could be useful in identifying individuals who are likely to be hindered by others due to competing resource requirements. Note that though both 
networks both reflect resource interdependence and may look equivalent, they emphasize different aspects of dependency and are useful for providing different inferences. Therefore, it is critical for researchers to properly specify the dependency network in a transparent fashion. We discuss the process and implications of characterizing both dependency network nodes and the relationship of dependence that form between them in more detail below.

\section{Deriving an Interdependence Network}

In our approach, deriving a dependency network occurs in three distinct steps. First, researchers develop or adopt an interdependence conceptualization. Second, they provide an explicit theoretical definition of what the interdependence relationships represent in their study based upon their interdependence conceptualization. Finally, they produce an operationalization based on their theoretical definition, which is used to gather data. We discuss each of these steps in more detail bellow.

Step 1: Conceptualization. There are many forms of interdependence, and therefore, using the term "interdependence" by itself is generally uninformative (Courtright et al., 2015; Pennings, 1975). Consider a study concerned with the effect of task-to-task relationships on team performance (e.g. inter-task coordination; O’Brien, 1968). Here, interdependence is almost certainly conceptualized as inter-task relationships. On the other hand, a different study may conceptualize interdependence as the number of social relationships that individuals hold within their team. The two conceptualizations will almost certainly generate two very different network representations. Although both network representations will reflect an aspect of interdependence, the conclusions drawn from a given representation will not generalize across different conceptualizations. Therefore, the first step in deriving a network of interdependence is to clearly state what the overarching concept of interdependence is within the context of the study (e.g. 
resource-interdependence, task-interdependence, outcome-interdependence, etc.). The conceptualization serves as an important role by grounding the notion of interdependence in existing forms and definitions of dependence found in the literature.

Step 2: Identify Theoretical Definition of Interdepedence. After the central conceptualization of interdependence is identified and clearly stated, a researcher should clearly identify the definition of dependency relationships that will be used to form a dependency network. In this step, the researcher develops a theoretical definition for what constitutes a dyadic dependency relationship, and its strength. The researcher should identify what is being connected (e.g. task, role, team etc.) and generally what the connection or dependency relationship itself represents (e.g. task assignments, social relationships, shared resources, etc.). In terms of the general definition of dependency we have provided, researchers should clearly specify the focal unit, source unit, and outcome of dependence as well as the general nature of the relationship. Though this step may seem trivial, without a clear specification of what "dependence" means for the specific study, researchers will run the risk of creating inaccurate or uninterpretable networks.

Step 3: Operationalization and Network Construction. Finally, the researchers should use their theoretical definition to develop an operationalization of interdependence, which will be used to generate an interdependence network. The operational definition provides a clear link between the theoretical definition of interdependence derived in Step 2, and the actual practice which will be employed by the researcher to collect data. A researcher may, for example, observe and behavioral counts that reflect interdependence (e.g. counting behaviors such as asking questions, helping or backing up behaviors, etc.). Alternatively, they may use a survey measures (e.g., self-reports, other-reports, etc.; Campion, Medsker \& Higgs, 1993; Morgeson \& 
Humphrey, 2006; Pearce \& Gregorsen, 1991). Another option is to consult with a subject matter experts (SME) or use theory to generate the dependency-network. In these instances, researchers may not directly assess interdependence, but may derive one from theoretical expectations based upon recommendations from SMEs or relevant organizational theory. It may be useful to combine multiple methods when constructing the dependency network. We emphasize that the procedure used for gathering the data must cohere with the conceptualization of interdependence and theoretical definition of the dependency relationship. For instance, a researcher using selfreports should include aspects of the instrument (e.g., perceptual aspect of interdependence) as part of the operational definition. Similarly, for observational studies, the operational definition should include rules dictating how behaviors will be counted and categorized.

By representing interdependence in terms of a network, researchers can evaluate interdependence based on a variety of network indices (Borgatti \& Halgin, 2011; Katz, Lazer, Arrow, \& Contractor, 2004). Each of these indices holds respective strengths and limitations, and as such their utility will depend on the nature of the researcher's investigation. In the following sections we propose raw and standardized indices for the general calculation of interdependence as well as a specific application of these indices related to degree-centrality.

\section{Indexing Interdependence}

As discussed above, dependency relationships reflect a connection between a focal unit and a source of dependency. There are numerous ways to index interdependence depending on the network characteristic of interest. A simple approach would involve calculating the sum of each dependency relationship held by a focal unit. For example, task interdependence may be the number of people who must complete tasks before the focal individual can perform their own tasks. This represents one approach to indexing the amount of interdependence in group; 
however, many other network characteristics can also be used to characterize interdependence.

For instance, the focal individual may depend on other individuals who in turn depend on the focal individual. In this case, the focal individual effectively depends on themselves (i.e., they are in a cycle; Wasserman \& Faust, 1994). Short cycle lengths indicate a higher degree of complexity and thus this may be a highly meaningful index of interdependence. Similarly, other indices such as tie strength, flows, clusters may also be relevant to studying interdependence (Borgatti \& Halgin, 2011; Park, et al., 2020). Therefore, in our discussion regarding indexing interdependence, we provide a general index, highlight its potential applications for calculating various network indices, and then provide a demonstration of how it can be used to calculate a degree-centrality based metric.

\section{General Interdependence Indices}

The first step in calculating a general index of interdependence is to calculate a raw score of interdependence. For simplicity we use RDI (i.e. the Raw Dependency Index) as a label for the raw value of a given network characteristic used to evaluate interdependence. To make interdependence scores comparable across studies, researchers will often employ a naïve normalization or standardization procedure to these raw scores based upon study-specific variance (cf. Morris \& DeShon, 2002). While naive normalization can meaningfully transform values to the same scale, comparing across studies based on this approach requires equivalence of sample variances, which may not hold in all situations. To avoid this issue, we can standardize the scores using theoretically derived parameters consistent across studies. Specifically, if we standardize based on a theoretical maximum score rather than a measure of variance, we can derive an index which has a consistent precise meaning for both 0 and 1 (whereas in the 
normalization approach, the meaning of 0 is constant, but the meaning of 1 can be samplespecific). We thus define the Standardized Dependency Index (SDI) as follows:

$$
\operatorname{SDI}\left(u_{i}\right)=\frac{R D I_{i}-\operatorname{mins}_{i}}{\max _{i}-\operatorname{mins}_{i}}
$$

where $u_{i}$ is a specific unit (i.e., the $i^{\text {th }}$ unit in the network), $R D I_{i}$ is the observed raw dependency score for $u_{i}, \max S_{i}$ is the theoretical maximum observable score for $u_{i}$, and $\min S_{i}$ is the theoretical minimum observable score for $u_{i}$.

Thus, $S D I$ is an unscaled representation of the maximal observed interdependence and is not based on a sample-specific distribution. Note that this approach differs from common social network analysis (SNA) approaches to standardization in at least two ways. First the SDI represents a general index compatible with many network indices and is therefore not identical to the standardized form of any one specific network index. In fact, the SDI is applicable to raw indices of interdependence that are not necessarily network-based at all (e.g. self-report questionnaires). In other words, SDI represents a general framework for standardized interdependence networks. Therefore, SDI scores can be meaningfully compared across studies and scales, given that the method for calculating the $R D I$ and determining a theoretical maximum and minimum remains consistent.

Second, our approach to calculating the theoretical maximum and minimum differs slightly from existing SNA approaches. Traditionally in a SNA, the maximum value represents the maximum interdependence score for any node in any network with the same number of nodes (Csardi \& Nepusz, 2006; Freeman, 1978; Wasserman \& Faust, 1994). Notably, the maximum may also be based on more restrictive criteria (e.g., the maximum value for the given index on all networks with the same number of nodes and a given number of connections). Regardless of the maximum value is calculated, it is used to standardize the entire network. In 
contrast, our approach frees these restrictions by allowing for cases where each node may have a different theoretical maximum and minimum score.

In many cases, researchers can assume that nodes all have the same theoretical maximum and minimum, and the SDI will therefore be equivalent to the traditional SNA approach. However, sometimes this assumption does not hold. This violation is clearly illustrated in cases where dependency relationships are described strictly between individuals and tasks. For example, consider instances when interdependence networks consist of two types of nodes: role and task. Further consider that relationships exist solely between different types of nodes (i.e., tasks must connect to roles and vice-versa). In this case, it is clear that theoretical maximum and minimum values would differ by node type. In this case, if there were $t$ tasks and $r$ roles, the theoretical maximum for any task-node would be $r$ (a given task-node can connect to all $r$ of the roles at most) and the theoretical maximum for any role would be $t$ (a given role can connect to all $t$ of the tasks at most). In contrast, the traditional approach would assume a maximum centrality score of $(t+r-1)$ for each network member, which would underestimate the centrality-based level of interdependence in the network. Therefore, we encourage researchers to explicitly discuss the theoretical maxima and minima for nodes present in their networks.

\section{Interdependence Centrality Index}

The general formulas above can flexibly provide raw and scaled scores for assessing any network characteristic representing group interdependence. Each characteristic provides unique information and the use of one characteristic over another depends on the goal of a given study. In the remainder of this section, we present a degree-centrality application of the SDI. We focus on centrality (and degree-centrality specifically) for a variety of reasons. 
First and most importantly, degree-centrality is consistent with existing approaches to measuring interdependence. In our review of measures, we found that most scales assessed how dependent (i.e., the amount of dependence) a focal unit is on other units. This form of assessment is most closely related to degree-centrality which reflects the number of connections between source and focal units. Indeed, in the workgroup literature, degree-centrality is a highly popular metric, and has been studied as an antecedent, mediator, moderator, and outcome in studies of leadership, performance, and employee voice behavior (see Park, et al., 2020 for a review). Relatedly, degree-centrality holds a relatively straightforward calculation procedure and interpretation, which makes it easy to implement and understand, increasing the likelihood of its usage in future investigations. We anticipate that most applications of the SDI score will be based on a degree-centrality raw score, and therefore provide a demonstration of its use.

Simple Networks. In cases where network connections are undirected, we can use a very simple form of the degree-centrality equation. Undirected networks refer to situations when all connections that make up the network flow equally in both directions. For instance, consider the case when individuals are asked to nominate who they communicate with most frequently. This could be seen as a form of informational based resource interdependence (e.g., Johnson et al., 1983; Rossi, 2008). In this situation, a researcher could construct an undirected network by connecting individuals to both anyone they nominated or anyone who nominated them. These connections would be undirected because the nominator and the nominated individuals are indistinguishable in the network representation and all connections flow in both directions equally. When all connections within a network are undirected, raw degree-centrality is reduced to a simple equation, mathematically defined as:

$$
D C\left(u_{i}\right)=\sum E_{i j}
$$


where $D C$ is the raw degree-centrality for a given unit, $u_{i}$ is a particular unit (i.e. individual, role, task, team, etc.), and $E_{i j}$ represents the strength of a dependency relationship between the focal unit (i.e. $u_{i}$ ) and another unit (i.e. $u_{i}$ ). The values for $E_{i j}$ therefore represent the strength of the relationships between the corresponding units. These values can range from 0 (representing absolutely no relationship) to 1 (representing maximal dependence). In many existing approaches, instead of encoding the strength of a given relationship, network connections represent simply the existence or non-existence of a dependency relationship. In this binary case the value of a give connection $E_{i j}$ will simply take a value of 0 when there is no connection and 1 where there is a connection. The equation is not otherwise adjusted.

In this case, the minimum degree-centrality for any given unit is simply 0 , and the maximum is one less than the number of units (i.e. each unit can be connected to every other unit, but not themselves). Mathematically, the simple SDI can be presented as:

$$
S D I_{C E N T}\left(u_{i}\right)=\frac{\sum E_{i j}}{n-1}
$$

where $S D I_{C E N T}$ represents the standardized degree-centrality of a given unit. The "CENT" subscript is included here to distinguish between other SDI scores that are not based on degreecentrality. By convention the subscript is dropped in cases where the degree-centrality-based SDI score is the only SDI score used. Finally, $n$ is the total number of units in the network; notice that any unit can have at most $n-1$ relationships to other units because it is assumed that units are not interdependent on themselves. This could be adjusted in the case where auto-dependence is meaningful.

General Networks. The equations for simple networks assume that relationships are undirected and that connections are theoretically possible between all units. In the general case 
these two assumptions may not be met. When researchers are concerned with the direction of dependence (cf. received or initiated dependence; Courtright, et al., 2015; Pearce \& Gregerson, 1991) or when certain dependence relationships are not possible within a network, researchers may wish to use an alternative form of the degree-centrality equation:

$$
D C\left(u_{i}\right)=\alpha \sum_{j} E_{i j}+(1-\alpha) \sum_{j} E_{j i}
$$

where $u_{i}$ represents a specific focal unit (as it did in Equation 3). $E_{i j}$ and $E_{j i}$ represent the strength of directional dependency relationship between the unit of interest (i.e. $\left.u_{i}\right)$ and another unit (i.e. $u_{i}$ ). Accordingly, $E_{i j}$ represents received dependency where the unit of interest depends on the other unit, and $E_{j i}$ represents initiated dependency where the other unit depends on the unit of interest. As previously, the values for both $E_{i j}$ and $E_{j i}$ can range from 0 (representing absolutely no relationship) to 1 (representing maximal dependence). Additionally, dependency will often be defined such that these values represent the existence or absence of a given relationship instead of the strength. As in previous equations, in this binary case the value of a given directed connection will simply take a value of 0 when there is no connection and 1 where there is a connection. Finally, $\alpha$ represents a weight that balances network in-degree and outdegree and takes any value from 0 to 1 . If the researcher is interested only in notions of received dependency, $\alpha$ will be set at 1 (thus eliminating the right hand term, $\frac{\sum_{j} E_{j i}}{N_{i}}$, from the equation), and if the researcher is only interested in notions of initiated dependency $\alpha$ will be set to 0 (thus eliminating the left hand term, $\frac{\sum_{j} E_{i j}}{N_{i}}$, from the equation). In general, unless there is a specific reason to focus only on received or initiated interdependence $\alpha$ will be set to $1 / 2$, thus equally balancing these two concepts. When all relationships are completely reciprocal $E_{i j}=E_{j i}$ and the equation can be simplified to a single term eliminating $\alpha$ as is the case in Equation 2 . 
In many cases, all units can theoretically have relationships with all other units. However, in complex dependency networks, connections may only be possible between certain units. For example, O’Brien's (1968) interpersonal coordination index is built on a network made up of roles and tasks. In this case, tasks can only be connected to roles, and roles can only be connected to tasks. For such networks, the maximum number of connections that a given unit can form equals the number of tasks when the focal unit is a role, and the number of roles when the focal unit is a task. Similarly, there may be a clear maximum to the number of relationships (either initiated or received) that a unit can form based on the given operationalization of interdependence. For example, if resources are restricted so that it can only be used by three people then the received of resources in a resource-dependency network would have a maximum value of 3. Likewise, in certain situations, either received or initiated dependence may have some minimum value. For example, if participants are asked to nominate at least three people that they give information to, the initiated dependence would be at least 3. SDI accounts for these constraints in the following equation.

$$
S D I_{C E N T}\left(u_{i}\right)=\alpha \frac{\sum_{j} E_{i j}-N_{i}^{[i n]}}{M_{i}^{[i n]}-N_{i}^{[i n]}}+(1-\alpha) \frac{\left.\sum_{j} E_{j i}-N_{i}^{[o u t ~}\right]}{\left.M_{i}^{[o u t]}-N_{i}^{[o u t ~}\right]}
$$

In this case, $N_{i}$ represents the minimum number of received (notated with [in]) or initiated (notated with $[o u t]$ ) dependency relationships that the focal unit (i.e. $u_{i}$ ) can have form. $M_{i}$ represents the maximum number of received (notated with [in]) or initiated (notated with [out]) dependency relationships that the focal unit (i.e. $u_{i}$ ) can have form. When reporting an SDI score, by convention, unless otherwise stated we assume that SDI refers to a centrality-based SDI score calculated using Equation 4 with $\alpha=\frac{1}{2}$. When focusing on received or initiated 
centrality (i.e. $\alpha=0$ or $\alpha=1$ ), this must be clarified explicitly. Likewise, if the SDI score is not based on a degree-centrality raw score this should be explicitly explained and noted.

\section{Moving Beyond Centrality}

Since centrality is one of the most popular network characteristics assessed in the organizational literature, we suggest calculating and reporting centrality-based scores. However, we also suggest that researchers consider other network indices that can provide more nuanced information regarding interdependence. Consider the individual level indices of eccentricity (an index measuring how distal members of a network are from the rest of the network), individual reciprocity (the proportion of connections that are reciprocated for that a give network member), and closeness (the average shortest path from a given network member to all other network members; Wasserman \& Faust, 1994). Although a comprehensive discussion of all possible network indices is beyond the scope of the current paper, we highlight that researchers can calculate an SDI for any such network characteristic and generate greater theoretical insight regarding interdependence and how they impact the individual and team.

Furthermore, SDI is valuable in providing a clear tool for moving beyond the individual level of analysis. Previous researchers have noted dyadic and network level research on interdependence has often been overlooked (Van Der Vegt \& Van De Vliert, 2002). SDI scores can be evaluated at node-, dyad-, and network levels, and can therefore facilitate investigations of higher-level interdependence. Network characteristics can be computed and standardized at all three levels (e.g. degree-centrality, connection strength, and density respectively represent node-, dyad-, and network-level characteristics; cf. Park, et al., 2020; Wasserman \& Faust, 1994). 
In these cases, the researcher can directly compute and analyze the SDI at the desired level of analysis, or they can aggregate lower-level indices to higher-levels based on existing multi-level recommendations (Chan, 1998; Kozlowksi \& Klein, 2000). Generally, the most common approach is to perform mean-based aggregation where the sum or mean of a lower level construct is used as a proxy for a higher-level construct (i.e., composition approach; Kozlowski, 2015; Woehr, Loignon, Schmidt, Loughry, \& Ohland, 2015). However, as is the case whenever researchers are aggregating constructs, researchers should take steps to ensure that aggregation is appropriate. If agreement is low, and variance is mostly partitioned at the individual level, this may not provide a meaningful metric (Kozlowski \& Klein, 2000). For this reason, we suggest that researchers report ICC and $\mathrm{R}_{\mathrm{wg}}$ scores at a minimum when justifying the use of mean-based aggregation for the node-level $S D I$. In cases where there is significant variability in unit-level SDI scores among individuals in a team, it may be meaningful to report the variability in team member SDI values in addition to a mean level aggregate value. The variability within the SDI scores may have a meaningful impact on other relationships of interest and is worth considering as a focal variable.

\section{Demonstrations of the Network Approach}

To contextualize our methodology, we provide two examples based on existing empirical work which is focused on interdependence. These examples will help to illustrate the process we are proposing and underline the power of this new framework to unify interdependence research. We will provide sample $R \operatorname{code}^{2}$ (R Core Team, 2015) for performing all operations described here. This code will reference two functions that are defined in Appendix A. Note that we

\footnotetext{
${ }^{2}$ Code for the functions used above is provide in appendix A. Additionally, Appendix B provides a full R-script that runs through the entire analysis for both this and the following example.
} 
consistent with the prior discussion we focus on using a degree-centrality-based SDI score, in addition to the aggregated form of $S D I_{C E N T}$ for each team.

\section{Example 1: Social Interdependence}

Conceptualization. Oetzel (2001) conducted a study investigating the impact of selfconstrual on group communication effectiveness and performance. The author elected to measure social interdependence in terms of interdependent self-construal, which assesses the extent to which individual internally represent their social context as a part of themselves. The broad conceptualization of interdependence used in this study is an individual based "connectedness" to one's group. More specifically we would suggest that interdependence would be conceptualized here as a social-cognitive understanding of one's relationship with their team. Notably the conceptualization used in this study focuses on how socially dependent the individual is on the shared group as a whole. In other words, interdependence is conceptualized here as individual-to-team aggregated relationships, not an individual-to-individual dyadic relationship or a relationship between an individual and their unique social context.

The conceptualization serves as the interface between the theoretical explanation on which a study is built and the way in which interdependence is measured. Explicitly stating the conceptualization of interdependence employed by the study allows us to consider the appropriateness of this conceptualization. If Oetzel had described the theoretical link between interdependence and communication based on dyadic relationships, a self-construal-based conceptualization would be inappropriate, because self-construal is focused on an individual's general connectedness to the group as a whole and not to specific individuals. 
Theoretical Definition. Based on the theory of self-construal, dependency here could be defined as the extent to which individuals form a self-understanding based on their relationship to others. Again, this is based on a general belief about one's relationships with others not based on dyadic relationships. Therefore, the theoretical relationships between the team and individual can be defined as reciprocal because there is no meaningful distinction between received and initiated self-construal. Note that many of the surveys found in our review contained items that defined interdependence as an individual's dependence to another person, and dependence to the team. Clarifying such inconsistencies is vital to properly representing interdependence as a network.

Operationalization. The operationalization of dependency relationships would be based directly on the self-construal scales used in the study, normalized so that a relationship a value of 1 represents an individual that maxes out the interdependence self-construal scale, and a value of 0 would represent the minimum possible score on the instrument. Figure 1 provides a visual representation of the dependency networks generated by this process for each team. In this case the dependency network for any one team will be a network-theoretical 'star' where all members of the network are connected to a single central network member which represents the aggregate team social context. All other network members would represent team members and the connection would represent a normalized self-construal scale score as discussed previously. The minimum and maximum values for a 5-point Likert scale will be 1 and 5 respectively.

\section{INSERT FIGURE 1 HERE}


Network Construction. In this section, we will explain how to construct a network from raw data. Data for this study could come in many formats, but one likely format has is an edge list format where each row represents a single edge. Each data row has a column for the participant ID (source), the target (target), and self-construal scale score (weight; see Table 2). Additionally, this data will likely hold a column indicating what team the individuals are members of (teamID). Because in the present example dependency relationships are all defined dyadically between individuals and the team the "target" and "teamID" columns are redundant. However, in scenarios where dependency relationships are not simply defined between an individual and the team, these columns will hold distinct information.

To illustrate this process, we use the igraph $\mathrm{R}$ package (Csardi \& Nepusz, 2006) to illustrate this process. First, we define a raw data set (See Table 2) then use the graph.data.frame() function to generate a graph object. This is analogous to generating a computerized representation of the dependency network. Note that for simplicity we construct a single R graph object that includes both teams in this example. In some applications it may be more appropriate or even necessary to calculate SDI scores for each team independently.

\section{INSERT TABLE 2 HERE}

\section{$R$ code:}

\section{library(igraph)}

rawSelfConstrualData = data.frame ( c('team1','team1','team1','team1','team2','team2','team2','team2','team2'), teamId = c('team1','team1','team1','team1','team2','team2','team2','team2','team2'), weight $=\mathrm{c}(3,4$, $5,5,2,1,1,2,1))$ 
scDependencyNetwork = graph. data.frame $($ rawSelfConstrualData, directed $=$ TRUE $)$

Calculating SDI. Oetzel was interested in a team-level aggregation of self-construal representing a notion of organizational construal culture. In the present dependency network representation, this concept of team self-construal is consistent with a degree-centrality-based $S D I$ score and can be represented in terms of the SDI score for the "team context" nodes in the network. To calculate the SDI values for each dependency network members we need 3 things. These are the raw dependency index or $R D I$, the theoretical maximum $R D I$ score for each node, and the theoretical minimum $R D I$ score for each node. The $R D I$ for each node can simply be calculated as a weighted degree-centrality score. Each team member is only connected to the central "team context" node and therefore have a theoretical maximum score of 5 (based on the Likert scale used in the survey). For the network nodes that represent the central team context, the theoretical maximum would occur when all team members had a maximal self-construal. This will be equal to $5 * n$ where $n$ is the number of team members. On the other hand, the theoretical minimum score for any team member is simply 1 , while the minimum score for the "team context" modes is equal to one for each team member or $n$ total.

Building on the previous work we provide a simple example for how this can be done in R. First, we use the strength() function from the igraph library to calculate the weighted vertex degree for each member of the dependency network. Next, we set the theoretical maximum and minimum raw dependency scores. Lastly, we use an sdi() function (defined in Appendix A) to uses these values to calculate the SDI scores. Results are seen in Table 3.

$R$ code:

RDI = strength $(\operatorname{scDependencyNetwork,~mode~}=$ "all") 


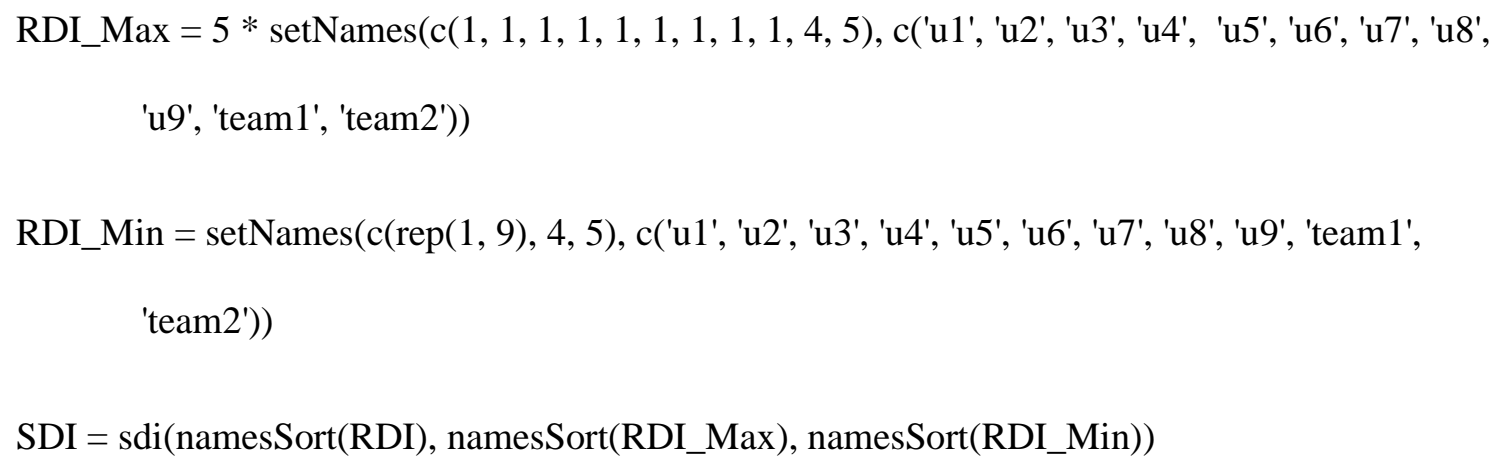

INSERT TABLE 3 HERE

\section{Example 2: Helping Behaviors}

Conceptualization. Barnes et al. (2008) studied the impact of backing up behaviors, which represents how one individual is dependent on another to perform their assigned tasks. Therefore, backing up behaviors can represent a form of task interdependence ${ }^{3}$. The authors conceptualized interdependence as a person-to-person measure assessing the extent to which individuals rely on other individuals to perform their specific tasks. Therefore, this is a different concept than Oetzel was concerned with, since Barnes and colleagues were focused on dyads rather than a relationship between an individual and the general team.

Theoretical definition. In this study, dependence relationships are theoretically defined by the amount of effort that one person put into performing another person's tasks. That is, the theoretical definition is not based on specific behaviors per se, but rather a more general "effort"

\footnotetext{
${ }^{3}$ Note that researchers could also describe helping behaviors in terms of role, resource, or social dependency if they desired. This ambiguity is precisely why we have focused on building a notion of dependency that can be defined independently of the theoretical nuances that researchers associate with their measures. In Barnes et al.'s study the focus was on the impact of interdependence on task performance; therefore, we will focus our discussion on this relationship.
} 
variable. This clarifies the theoretical connection to other variables of interest. In this case effort expended helping another will reduce one's performance on their own tasks.

Operational Definition. Dependency relationships are operationally defined in this study according to the observed number of times that team members perform each other's tasks. The operational definition here provides very specific rules regarding what behaviors are counted, and how. In this case the definition describes the behaviors that would fall under the term "helping" behavior, and how these behaviors will be counted. It is common in scenarios similar to this study to use an interval-based binning procedure where the reported behavioral count would represent the number of intervals in which at least one helping behavior was observed. If an interval-based procedure was used, this could be used to establish the contextual minimum and maximum values for dependency relationship. For example, this study uses 30-minute long sessions. If we bin behaviors into 30 distinct one-minute intervals, we would define the conceptual maximum number of helping behaviors as 30 and the minimum as 0 . For the purposes of illustration, and without a clearer understanding of the procedure used in this study, we will continue with this arbitrarily selected range.

\section{INSERT FIGURE 2 HERE}

Constructing a Network. After collecting data, developing a dependency network is straight forward (Figure 2). As in the self-construal example, there are many forms that the raw data could take. We will assume that data is presented in an edge list format with two rows for each participant pairing (i.e., one for each direction of helping: A helping B and B helping A). There are columns for the participant id (source), the person they help (target), the team they are 
in (teamId), and the number of observed helping behaviors (weight). In our script example below, we again instantiate example data and generate a $\mathrm{R}$ graph object which serves as a computerized representation of the dependency network.

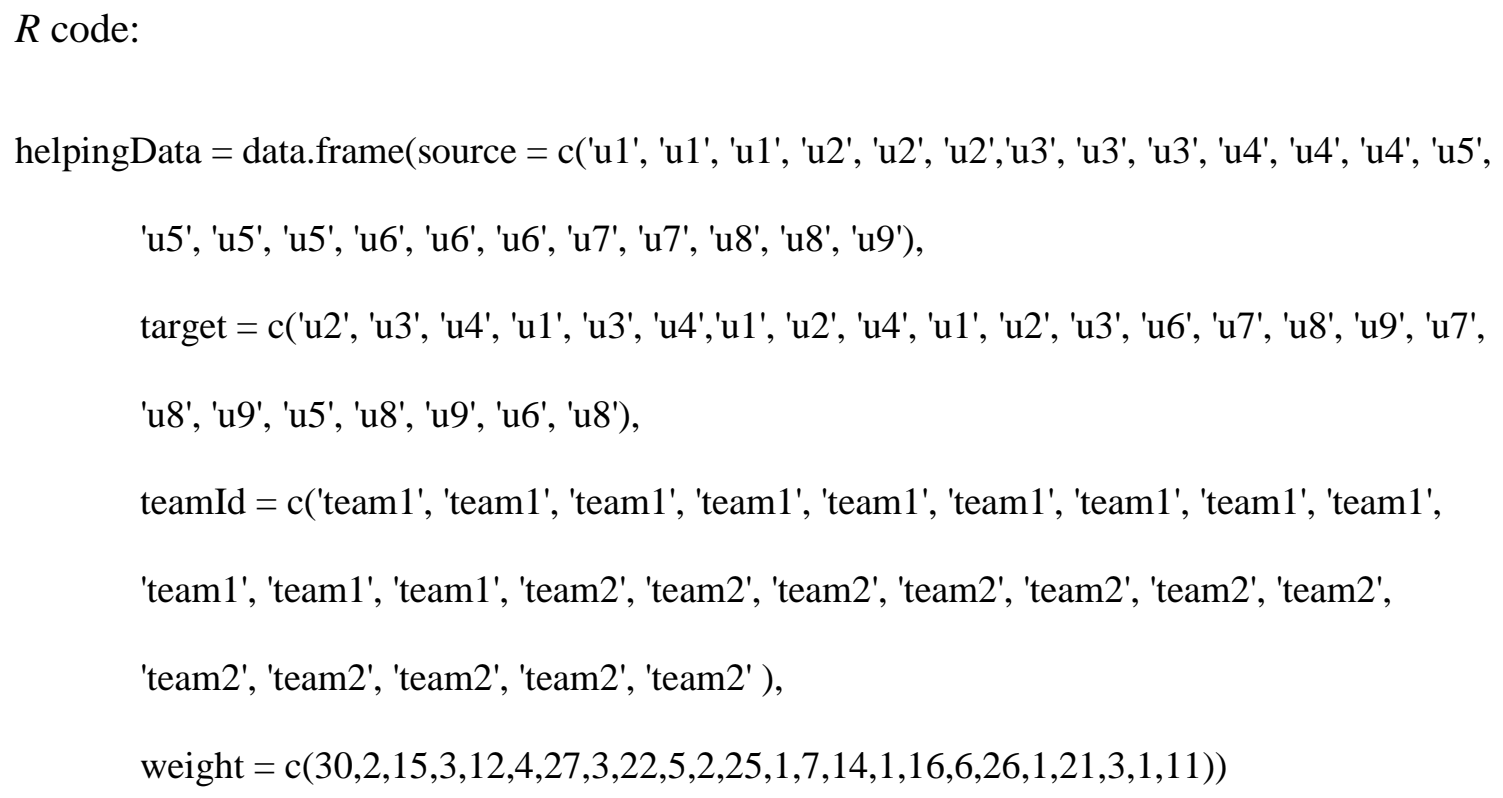

INSERT TABLE 4 HERE

Calculating SDI. The focus of this study on the overall impact of individuals helping others is consistent again with the notion of degree-centrality, as such we will use a weighted degree-centrality-based SDI to index interdependence. However, here it may be meaningful to consider both in- and out-degree-centrality. For these reasons we will calculate two SDI scores. This is equivalent to using Equation 5 with $\alpha=0$, and $\alpha=1$. After calculating raw dependency scores, we must assess theoretical minimum and maximum scores. In the previous example there were different theoretical maximum and minimum scores for the team context and individual dependency network nodes. In this example, however, all members of the same team will have 
the same theoretical maximum. This is 30 helping behaviors per other person or $30 *(n-1)$. It should be noted that depending on the nature of the work and helping behaviors, it is possible that helping one person would make it impossible to help another person in the same time period, which would suggest a more stringent theoretical maximum (i.e., the theoretical maximum would simply be 30). Similarly, it is possible that individuals had different levels of exposure to each other. For instance, during a 30-minute observation period one person may have only been present for 15 minutes, this would suggest a much more stringent maximum (e.g. max $=$ 15(n-1) ). There are many possibilities, and therefore the theoretical maximum chosen should meaningfully represent maximal interdependence for the given research question.

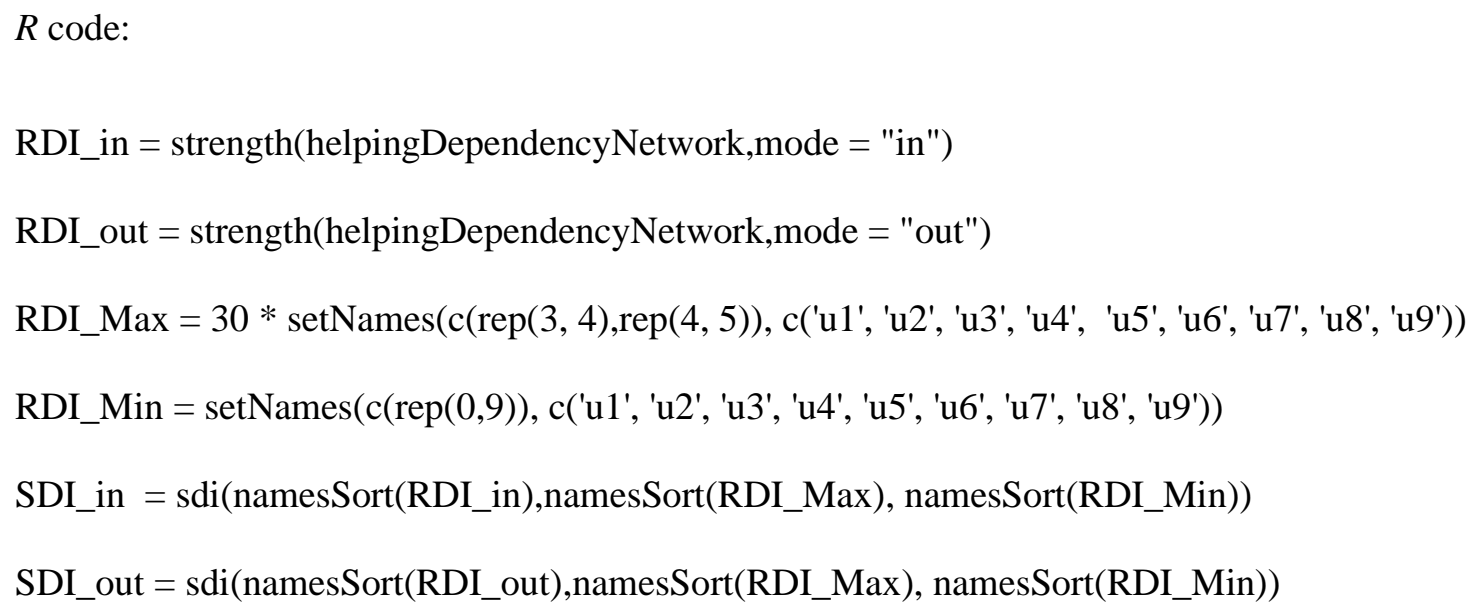

INSERT TABLE 5 HERE

\section{Comparing SDI Scores.}

The two examples evaluate very different forms of interdependence. However, it is possible to qualitatively compare the results across the two examples because they use a standardized metric of dependency. For example, the SDI scores in the two networks and 
identify Member 1 and Member 3, in the first and second examples respectively, as highly interdependent within their own context. Furthermore, if two studies use the same RDI to calculate an SDI score, their values can be directly compared. For instance, if we used a nondirected degree-centrality SDI score in example 2 the score could be used to compare results in example 1 on a quantitative level.

\section{Recommendations}

There exists a plethora of scale- and study-specific methods for calculating interdependence, which impede cross-study comparison and the accumulation of knowledge. To resolve this issue, we provide a method for calculating interdependence across constructs and measures. Given a clear conceptualization of interdependence and operationalization of the subsequent interdependence network, the SDI provides a unifying and unscaled interpretation of the magnitude of interdependence. Some recommendations for its use are provided below.

\section{Recommendation 1: Match theory to operationalization of interdependence.}

It is important to properly aligns theoretical concepts with the actual operationalization of interdependence. Operationalizations of network connections can be uninterpretable unless they are mapped onto an existing theory of interdependence, in the same manner that operationalizations of constructs (e.g., planning office parties) are uninterpretable unless they reflect some theoretically justified aspect of that construct (e.g., citizenship behaviors). However, when researchers are seeking to identify new aspects of interdependence that have not been captured, then they may proceed with our approach in an exploratory fashion. That is, they may operationalize network connections (e.g., communication) and then use the pattern of those connections to abstract a theory post-hoc (e.g., communication reflects interdependence). However, this approach should be clearly noted and stated as exploratory. 


\section{Recommendation 2: Discuss interdependence in terms of a network.}

We advocate for researchers' explicit discussion of interdependence as a network for two reasons. First, it is important to use a common language when measuring different aspects of interdependence so that research is able to accumulate and integrate. Using network language is our attempt to introduce a common language that can help unify the currently disparate research areas of interdependence. By describing connections between nodes in terms of degreecentrality, researchers have a common means to talk about outcome, received, initiated, and other related interdependence constructs. These interdependence constructs reflect different configurations of the same nodes and connections. Talking about these constructs in terms of networks can help identify areas of similarity and difference, identify construct redundancy, and clarify conceptual and practical differences in the manifestation of interdependence constructs. Relatedly, an explicit discussion of interdependence as a network lends itself to a pictorial representation that will make it easier for readers to understand the flow of interdependence within a team or organization.

\section{Recommendation 3: Report interdependence in terms of SDI values.}

The primary benefit of the $S D I$ is its generalizability in capturing all interdependence constructs. Therefore, we strongly advocate for representing and reporting interdependence values in terms of $S D I$ values. For example, if a study focuses on task-interdependence, the $S D I$ should be represented as "task-SDI". If directionality is important (e.g., the study focuses on received interdependence not initiated) then this should also be stated (e.g., "received taskSDI"). This allows for a general reporting method which can be used across different interdependence constructs and across different operationalizations of the same interdependence construct. In this way, researchers will be able to accumulate and integrate interdependence 
research. We extend this recommendation across levels as well. Our equations reflect both unit and network level approaches to identifying interdependence, and both levels are important to understand. It may be that there is one individual that drives network-level interdependence upward due to the centrality of their role. Conversely, it might be that dependence is distributed evenly throughout the network. Even though the two networks in aggregate may have the same interdependent scores, individual-level scores may be vastly different based upon the configuration of roles (Humphrey, et al., 2012). Understanding these differences will prove useful for researchers that seek to investigate differences in interdependence across levels and will help identify nuances in the effects or associations of interdependence with other constructs.

\section{Recommendation 4: Report SDI scores even when they are not focal variables.}

In many studies, researchers reference one situation, team, or structure as more highly interdependent then another. For example Shifflett (1972) describes how teams' interdependence is related to their vertical and horizontal structures. In such cases, interdependence is not a focal antecedent or outcome variable. Instead, it is an important characteristic of interest for the study. The SDI provides a powerful means to give justification for descriptions such as "highly interdependent" or "interconnected", etc. In such cases we would suggest that it is straightforward to follow the pattern describe in this paper to form a conceptualization, theoretical definition, and operationalization for such structures and provide an SDI score. Doing so provides a strong empirical justification for a claim of interdependence, and a clear theoretical explanation of how interdependence is related to the scope of a study.

\section{Recommendation 5: Develop indices that go beyond centrality.}

Network structures can be characterized by numerous indices beyond centrality (e.g., reciprocity, clustering, modularity, and connectivity). For the sake of unity, and for its previously 
discussed merits, we strongly encourage using the degree-centrality-based SDI (note that this can be referred to as $S D I_{C E N T}$ when it is ambiguous). However, our procedure for representing interdependence as a network enables researchers to consider a much broader world of interdependence. Each structural index of a network can provide unique and valuable insights into the nature of the network. For example, centrality can reflect the importance of a member to a team. This is broadly applicable to most interdependence research. Connectivity is quite different. It is a measure of how many edges or nodes would need to be removed to separate different parts of a network. Teamwork processes with a low level of workflow dependency network connectivity would be easier to separate and compartmentalize than processes with a higher degree of workflow dependency network connectivity. This network index could be incorporated as a raw score into a score for $S D I_{C O N N E C T}$. The clustering coefficient of a network is yet another uniquely informative index which, provides a measure of the propensity of a network to form clusters or closely interdependent groups. Interpersonal dependency networks with a high degree of clustering indicate a cliquey interpersonal group, which may have important implications for how ideas, and errors propagate through the group. This could be incorporated as a raw score into a score for $S D I_{C L U S T E R}$. Each of these or numerous other options would maintain the unifying power of the SDI while allowing theoretically important focuses. We suggest that there is tremendous potential in using such indices to move beyond naive degree-centrality-based measures of interdependence.

\section{Applications for Future Research}

The network perspective of interdependence provides some promising applications for the study of interdependence. Specifically, theories of interdependence pose interdependence constructs as relational aspects of actors (i.e., tasks or people, or both) embedded within a given 
social context. Specific examples of potential applications include focusing on the pattern of interconnections that exist within a team, how these connections are embedded within a given workflow or social network, and whether changes to these connections impact members uniformly or asymmetrically based upon their role (cf. Humphrey, Morgeson, \& Mannor, 2009). Additionally, a more general direction would use the network perspective to conceptualize teams in terms of having a single general dependency network, which manifests in various configurations depending on which aspect of interdependence is more relevant to study. Therefore, instead of identifying different types of interdependence constructs, researchers can use our framework to study interdependence as a unified construct. Although its specific facets (i.e., configurations) may change, the underlying amount of interdependence (i.e., the SDI value) will remain interpretable and comparable across different configurations. This approach could help formulate a general theory of interdependence.

As a common metric for interdependence, the SDI also provides analytical benefits. First, researchers can use the SDI associated with specific constructs as covariates in observational and experimental designs when assessing the predictive validity of interdependence on group outcomes. This will help identify the relative importance of interdependence in comparison to other indicators of interpersonal (e.g., communication, conflict), action (e.g., monitoring), or transition (e.g., planning) processes. Similarly, interdependence can be examined as a moderating variable on the relative impact of these group processes on important group outcomes (e.g., performance). Finally, interdependence can represent a process in and of itself, and help explain why group compositions or structures may facilitate or inhibit performance.

Moreover, the SDI can assess how structural features of the group impacts the group's performance. Specifically, researchers can assess how changes to the group's structure may 
change one network configuration of interdependence (e.g., social), but have no impact on other interdependence aspects (e.g., task). Similarly, researchers that are concerned with interdependence as a potential confound can include the $S D I$ as a control variable. Finally, as a common metric, the SDI provides researchers with a common variable to include in analyses. As an unscaled effect size, SDI scores can help further meta-analytic studies on the impact of interdependence. Lastly, as discussed throughout the paper, an explicit focus on networks highlights the potential application of future metrics and indices that focus on more complex aspects of interdependence. The extant literature has focused primarily on the importance of units in their network, which closely aligns with the notion of centrality. However, more interesting, novel, and potentially useful insights can be gleaned through the use of more complex network indices (cf. Park, et al., 2020). The derivation and application of these indices will certainly require a network representation of interdependence.

\section{Conclusion}

The importance of interdependence continues to grow as organizations increasingly move to team-based configurations to meet highly complex task demands. For researchers in this area, there is a pressing need for a uniform method and metric for evaluating interdependence. It is our hope that our network approach and the SDI helps researchers and practitioners by ensuring that they are using a common, objective method for evaluating interdependence - and the many forms it can take.

\section{Acknowledgments}

We gratefully acknowledge assistance provided by Zachary Neal as we framed the ideas presented in this manuscript. 


\section{References}

Agnew, C. R., Van Lange, P. A. M., Rusbult, C. E., \& Langston, C. A. (1998). Cognitive Interdependence: Commitment and the Mental Representation of Close Relationships. Journal of Personality and Social Psychology, 74(4), 939-954.

Aktipis, A., Cronk, L., Alcock, J., Ayers, J. D., Baciu, C., Balliet, D., Boddy, A. M., Curry, O. S., Krems, J. A., Muñoz, A., Sullivan, D., Sznycer, D., Wilkinson, G. S., \& Winfrey, P. (2018). Understanding cooperation through fitness interdependence. Nature Human Behaviour, 2(7), 429-431. https://doi.org/10.1038/s41562-018-0378-4

Amaral, L. A. N., Scala, A., Barthelemy, M., \& Stanley, H. E. (2000). Classes of small-world networks. Proceedings of the national academy of sciences, 97(21), 11149-11152.

Ariel, S. (2000). Team dispersion: The effect of geographical dispersion team process and performance (Ph.D. thesis). Stanford University, United States - California.

Aron, A., Aron, E. N., \& Smollan, D. (1992). Inclusion of Other in the Self Scale and the Structure of Interpersonal Closeness. Journal of Personality and Social Psychology, 63(4), 596-612.

Ashworth, M. J. (2007). Computational and empirical explorations of work group performance (Ph.D. thesis). Carnegie Mellon University, United States - Pennsylvania.

Balkundi, P., \& Kilduff, M. (2006). The ties that lead: A social network approach to leadership. The leadership quarterly, 17(4), 419-439.

Balliet, D., Tybur, J. M., \& Van Lange, P. A. M. (2017). Functional Interdependence Theory: An Evolutionary Account of Social Situations. Personality and Social Psychology Review, 21(4), 361-388. https://doi.org/10.1177/1088868316657965 
Barnes, C. M., Hollenbeck, J. R., Wagner, D. T., DeRue, D. S., Nahrgang, J. D., \& Schwind, K. M. (2008). Harmful help: The costs of backing-up behavior in teams. Journal of Applied Psychology, 93(3), 529-539.

Beauchamp, M. R., \& Bray, S. R. (2001). Role ambiguity and role conflict within interdependent teams. Small Group Research, 32(2), 133-157.

Beauchamp, M. R., Bray, S. R., Eys, M. A., \& Carron, A. V. (2002). Role ambiguity, role efficacy, and role performance: Multidimensional and mediational relationships within interdependent sport teams. Group Dynamics: Theory, Research, and Practice, 6(3), 229.

Blanton, H., \& Jaccard, J. (2006). Arbitrary metrics in psychology. American Psychologist, 61(1), 27-41.

Campion, M. A., Medsker, G. J., \& Higgs, A. C. (1993). Relations between work group characteristics and effectiveness: Implications for designing effective work groups. Personnel psychology, 46(4), 823-847.

Carter, D. R., DeChurch, L. A., Braun, M. T., \& Contractor, N. S. (2015). Social network approaches to leadership: An integrative conceptual review. Journal of Applied Psychology, 100(3), 597-622.

Carter, N. T., Lowery, M. R., Williamson Smith, R., Conley, K. M., Harris, A. M., Listyg, B., ... \& Carter, D. R. (2019). Understanding job satisfaction in the causal attitude network (CAN) model. Journal of Applied Psychology. 105(9), 959993. https://doiorg.proxy1.cl.msu.edu/10.1037/ap10000469

Cataldo, M., Mockus, A., Roberts, J. A., \& Herbsleb, J. D. (2009). Software Dependencies, Work Dependencies, and Their Impact on Failures. IEEE Transactions on Software Engineering, 35(6), 864-878. https://doi.org/10.1109/TSE.2009.42 
Chan, D. (1998). Functional relations among constructs in the same content domain at different levels of analysis: A typology of composition models. Journal of applied psychology, 83(2), 234-246.

Chen, G., \& Kanfer, R. (2006). Toward a Systems Theory of Motivated Behavior in Work Teams. Research in Organizational Behavior, 27, 223-267. https://doi.org/10.1016/S0191-3085(06)27006-0

Courtright, S. H., Thurgood, G. R., Stewart, G. L., \& Pierotti, A. J. (2015). Structural interdependence in teams: An integrative framework and meta-analysis. Journal of Applied Psychology, 100(6), 1825-1846. https://doi.org/10.1037/apl0000027

Cronk, L., Steklis, D., Steklis, N., van den Akker, O. R., \& Aktipis, A. (2019). Kin terms and fitness interdependence. Evolution and Human Behavior, 40(3), 281-291. https://doi.org/10.1016/j.evolhumbehav.2018.12.004

Cross, S. E., Bacon, P. L., \& Morris, M. L. (2000). The Relational-Interdependent Self-Construal and Relationships. Journal of Personality and Social Psychology, 78(4), 791-808.

Csardi, G., \& Nepusz, T. (2006). The igraph software package for complex network research. InterJournal, Complex Systems, 1695(5), 1-9.

Davis, B. A., \& Weigel, D. J. (2019). Cognitive interdependence and the everyday expression of commitment. Journal of Social and Personal Relationships, 37(3), 1008-1029. 026540751988464. https://doi.org/10.1177/0265407519884640

Davison, R. B., Hollenbeck, J. R., Barnes, C. M., Sleesman, D. J., \& Ilgen, D. R. (2012). Coordinated action in multiteam systems. Journal of Applied Psychology, 97(4), 808824. https://doi.org/10.1037/a0026682 
De Dreu, C. K., \& West, M. A. (2001). Minority dissent and team innovation: The importance of participation in decision making. Journal of applied Psychology, 86(6), 1191.

Embretson, S. E. (2006). The continued search for nonarbitrary metrics in psychology. American Psychologist, 61(1), 50-55. https://doi-org.proxy1.cl.msu.edu/10.1037/0003$\underline{066 X .61 .1 .50}$

Freeman, L. C. (1978). Centrality in social networks conceptual clarification. Social Networks, 1(3), 215-239. https://doi.org/10.1016/0378-8733(78)90021-7

Girvan, M., \& Newman, M. E. (2002). Community structure in social and biological networks. Proceedings of the national academy of sciences, 99(12), 7821-7826.

Hollenbeck, J. R., Beersma, B., \& Schouten, M. E. (2012). Beyond Team Types and Taxonomies: A Dimensional Scaling Conceptualization for Team Description. Academy of Management Review, 37(1), 82-106. https://doi.org/10.5465/amr.2010.0181

Humphrey, S. E., Morgeson, F. P., \& Mannor, M. J. (2009). Developing a theory of the strategic core of teams: A role composition model of team performance. Journal of applied psychology, 94(1), 48-61.

Jackson, M. O. (2014). Networks in the understanding of economic behaviors. Journal of Economic Perspectives, 28(4), 3-22.

Janssen, O., Van De Vliert, E., \& Veenstra, C. (1999). How task and person conflict shape the role of positive interdependence in management teams. Journal of Management, 25(2), 117-141. doi:10.1016/S0149-2063(99)80006-3

Jehn, K. A., \& Chatman, J. A. (2000). The Influence Of Proportional And Perceptual Conflict Composition On Team Performance. International Journal of Conflict Management, 11(1), 56-73. 
Jeong, H., Tombor, B., Albert, R., Oltvai, Z. N., \& Barabási, A. L. (2000). The large-scale organization of metabolic networks. Nature, 407(6804), 651-654.

Johnson, D. W., Johnson, R., \& Anderson, D. (1983). Social Interdependence and Classroom Climate. The Journal of Psychology, 114(1), 135-142. https://doi.org/10.1080/00223980.1983.9915406

Katz, N., \& Lazer, D. (2014). Building effective intra-organizational networks: The role of teams (Working paper). Cambridge, MA: Center for Public Leadership.

Kiggundu, M. N. (1981). Task interdependence and the theory of job design. Academy of management Review, 6(3), 499-508.

Kozlowski, S. W. (2015). Advancing research on team process dynamics: Theoretical, methodological, and measurement considerations. Organizational Psychology Review, 5(4), 270-299.

Kozlowski, S. W. J., \& Bell, B. S. (2003). Work groups and teams in organizations. In Organizational Psychology (pp. 412-469).

Kozlowski, S. W. J., \& Klein, K. J. (2000). A multilevel approach to theory and research in organizations: Contextual, temporal, and emergent processes. In K. J. Klein \& S. W. J. Kozlowski (Eds.), Multilevel theory, research, and methods in organizations: Foundations, extensions, and new directions (p. 3-90). Jossey-Bass.

Landis, B. (2016). Personality and social networks in organizations: A review and future directions. Journal of Organizational Behavior, 37, S107-S121.

Lee, S. H., Shin, Y., \& Kim, M. (2018). Why work meaningfulness alone is not enough: The role of social identification and task interdependence as facilitative boundary conditions. Current Psychology, 1-17. https://doi.org/10.1007/s12144-018-0027-0 
Lee, S. M., Koopman, J., Hollenbeck, J. R., Wang, L. C., \& Lanaj, K. (2015). The Team Descriptive Index (TDI): A Multidimensional Scaling Approach for Team Description. Academy of Management Discoveries, 1(1), 91-116. https://doi.org/10.5465/amd.2013.0001

Lenox, M. J., Rockart, S. F., \& Lewin, A. Y. (2007). Interdependency, competition, and industry dynamics. Management Science, 53(4), 599-615.

Liden, R. C., Wayne, S. J., \& Bradway, L. K. (1997). Task interdependence as a moderator of the relation between group control and performance. Human Relations, 50(2), 169-181.

Mahoney, J. (2000). Path Dependence in Historical Sociology. Theory and Society, 29(4), 507548. JSTOR.

Marks, M. A., Mathieu, J. E., \& Zaccaro, S. J. (2001). A Temporally Based Framework and Taxonomy of Team Processes. Academy of Management Review, 26(3), 356-376.

Mathieu, J. E., Tannenbaum, S. I., Donsbach, J. S., \& Alliger, G. M. (2014). A Review and Integration of Team Composition Models: Moving Toward a Dynamic and Temporal Framework. Journal of Management, 40(1), 130-160. https://doi.org/10.1177/0149206313503014

Mohr, L. B. (1971). Organizational technology and organizational structure. Administrative science quarterly, 16(4), 444-459.

Morgeson, F. P., \& Humphrey, S. E. (2006). The Work Design Questionnaire (WDQ): developing and validating a comprehensive measure for assessing job design and the nature of work. Journal of applied psychology, 91(6), 1321-1339. 
Niiya, Y., \& Crocker, J. (2019). Interdependent = Compassionate? Compassionate and SelfImage Goals and Their Relationships With Interdependence in the United States and Japan. Frontiers in Psychology, 10, 192. https://doi.org/10.3389/fpsyg.2019.00192

O’Brien, G. (1968). The measurement of cooperation. Organizational Behavior and Human Performance, 3(4), 427-439. https://doi.org/10.1016/0030-5073(68)90019-6

Oetzel, J. G. (2001). Self-construals, communication processes, and group outcomes in homogeneous and heterogeneous groups. Small group research, 32(1), 19-54.

Onwuegbuzie, A. J., \& Daley, C. E. (1998). Study Skills of Undergraduates as a Function of Academic Locus of Control, Self-Perception, and Social Interdependence. Psychological Reports, 83(2), 595-598. https://doi.org/10.2466/pr0.1998.83.2.595

Oeser, O. A., \& Harary, F. (1962). A mathematical model for structural role theory, i. Human Relations, 15(2), 89-109.

Oeser, O. A., \& Harary, F. (1964). A mathematical model for structural role theory, ii. Human Relations, 17(1), 3-17.

Oeser, O. A., \& O’Brien, G. (1967). A mathematical model for structural role theory, iii. Human Relations, 20(1), 83-97.

Page, S. E., Bramson, A., Bednar, J., Grzymala-Busse, A. M., \& Hacker, J. S. (2006). Path Dependence. Quarterly Journal of Political Science, 1(1), 87-115.

Papiotis, P., Marchini, M., Perez-Carrillo, A., \& Maestre, E. (2014). Measuring ensemble interdependence in a string quartet through analysis of multidimensional performance data. Frontiers in Psychology, 5, 963. https://doi.org/10.3389/fpsyg.2014.00963

Park, S., Mathieu, J. E., \& Grosser, T. J. (2020). A network conceptualization of team conflict. Academy of Management Review, 45(2), 352-375. 
Pearce, J. L., \& Gregersen, H. B. (1991). Task interdependence and extrarole behavior: A test of the mediating effects of felt responsibility. Journal of Applied Psychology, 76(6), 838844. https://doi.org/10.1037/0021-9010.76.6.838

Pearsall, M. J., Christian, M. S., \& Ellis, A. P. (2010). Motivating interdependent teams: Individual rewards, shared rewards, or something in between? Journal of Applied Psychology, 95(1), 183-191.

Pennings, J. M. (1975). Interdependence and Complementarity-The Case of a Brokerage Office. Human Relations, 28(9), 825-840. https://doi.org/10.1177/001872677502800904

R Core Team. (2015). R: A language and environment for statistical computing. Vienna, Austria: R Foundation for Statistical Computing.

Roberson, Q. M., \& Colquitt, J. A. (2005). Shared and configural justice: A social network model of justice in teams. Academy of Management Review, 30(3), 595-607.

Rossi, M. (2008). The Development and Validation of the Comprehensive Team Interdependence Scale (M.A. thesis). University of South Florida, United States - Florida. https://scholarcommons.usf.edu/etd/481

Shiflett, S. C. (1972). Group Performance as a Function of Task Difficulty and Organizational Interdependence. Organizational Behavior and Human Performance, 7(3), 442-456. https://doi.org/10.1016/0030-5073(72)90028-1

Singelis, T. M. (1994). The Measurement of Independent and Interdependent Self-Construals. Personality and Social Psychology Bulletin, 20(5), 580-591. https://doi.org/10.1177/0146167294205014 
Somech, A. (2008). Managing Conflict in School Teams: The Impact of Task and Goal Interdependence on Conflict Management and Team Effectiveness. Educational Administration Quarterly, 44(3), 359-390. https://doi.org/10.1177/0013161X08318957

Sparrowe, R. T. (2014). Leadership and social networks: Initiating a different dialog. In D. Day (Ed.), The Oxford handbook of leadership and organizations. New York, NY: Oxford University Press.

Thompson, J. (1967) Organizations in action. New York: McGraw-Hill.

Tjosvold, D. (1986). The dynamics of interdependence in organizations. Human Relations, 39(6), 517-540.

Tjosvold, D., Tang, M. M. L., \& West, M. (2004). Reflexivity for Team Innovation in China: The Contribution of Goal Interdependence. Group \& Organization Management, 29(5), 540-559. https://doi.org/10.1177/1059601103254911

Van de Ven, A. H. (1976). A framework for organization assessment. Academy of management Review, 1(1), 64-78.

Van Der Vegt, G., Emans, B., \& Van De Vliert, E. (2000). Team Members’ Affective Responses to Patterns of Intragroup Interdependence and Job Complexity. Journal of Management, 26(4), 633-655. doi: $10.1177 / 014920630002600403$

Van Der Vegt, G. S., \& Van De Vliert, E. (2002). Intragroup interdependence and effectiveness: Review and proposed directions for theory and practice. Journal of Managerial Psychology, 17, 50-68.

Van Der Vegt, G. S., Van De Vliert, E., \& Oosterhof, A. (2003). Informational Dissimilarity and Organizational Citizenship Behavior: The Role of Inatrateam Interdependence and Team 
Identification. The Academy of Management Journal, 46(6), 715-727. JSTOR. https://doi.org/10.2307/30040663

Victor, B., \& Blackburn, R. S. (1987). Interdependence: An alternative conceptualization. Academy of Management Review, 12(3), 486-498.

Vignoles, V. L., Owe, E., Becker, M., Smith, P. B., Easterbrook, M. J., Brown, R., González, R., Didier, N., Carrasco, D., Cadena, M. P., Lay, S., Schwartz, S. J., Des Rosiers, S. E., Villamar, J. A., Gavreliuc, A., Zinkeng, M., Kreuzbauer, R., Baguma, P., Martin, M., ... Bond, M. H. (2016). Beyond the 'east-west' dichotomy: Global variation in cultural models of selfhood. Journal of Experimental Psychology: General, 145(8), 966-1000. https://doi.org/10.1037/xge0000175

Wageman, R. (1995). Interdependence and Group Effectiveness. Administrative Science Quarterly, 40(1), 145-180. https://doi.org/10.2307/2393703

Wageman, R., \& Gordon, F. M. (2005). As the Twig Is Bent: How Group Values Shape Emergent Task Interdependence in Groups. Organization Science, 16(6), 687-700.

Wasserman, S., \& Faust, K. (1994). Social network analysis: Methods and applications (Vol. 8). Cambridge university press.

White, H. C. (1995). Social networks can resolve actor paradoxes in economics and in psychology. Journal of Institutional and Theoretical Economics (JITE)/Zeitschrift für die gesamte Staatswissenschaft, 58-74.

Williams, R. J., \& Martinez, N. D. (2004). Stabilization of chaotic and non-permanent food-web dynamics. The European Physical Journal B, 38(2), 297-303.

Woehr, D. J., Loignon, A. C., Schmidt, P. B., Loughry, M. L., \& Ohland, M. W. (2015). Justifying aggregation with consensus-based constructs: A review and examination of 
cutoff values for common aggregation indices. Organizational Research Methods, 18(4), 704-737.

Wong, C. S., \& Campion, M. A. (1991). Development and test of a task level model of motivational job design. Journal of Applied Psychology, 76(6), 825-837.

Wood, R. E. (1986). Task complexity: Definition of the construct. Organizational Behavior and Human Decision Processes, 37(1), 60-82. doi:10.1016/0749-5978(86)90044-0

Zhang, Z. X., Hempel, P. S., Han, Y.-L., \& Tjosvold, D. (2007). Transactive memory system links work team characteristics and performance. Journal of Applied Psychology, 92(6), 1722. 
Table 1. Selected review of interdependence measures.

\begin{tabular}{|c|c|c|c|c|}
\hline Measure & \begin{tabular}{|c|}
$\begin{array}{c}\text { Interdependence } \\
\text { Construct }\end{array}$ \\
\end{tabular} & $\begin{array}{c}\text { Focal } \\
\text { Unit } \\
\end{array}$ & Source Unit & $\begin{array}{c}\text { Measure } \\
\text { Type }\end{array}$ \\
\hline $\begin{array}{l}\text { Morgeson \& Humphrey, } 2006(\mathrm{~A}) \\
\text { - } \quad \text { The job requires me to accomplish my job before others } \\
\text { complete their job } \\
\text { - } \quad \text { Unless my job gets done, other jobs cannot be completed }\end{array}$ & Initiated & Individual & Individual & Survey \\
\hline $\begin{array}{l}\text { Morgeson \& Humphrey, } 2006(\mathrm{~B}) \\
\text { - } \quad \text { The job depends on the work of many different people for its } \\
\text { completion } \\
\text { - My job cannot be done unless others do their work }\end{array}$ & Received & Individual & Individual & Survey \\
\hline $\begin{array}{l}\text { Wong \& Campion, } 1991 \\
\text { - How well one task is performed has a great effect on how well } \\
\text { the other task can be performed } \\
\text { - One task needs to be performed before the other task }\end{array}$ & Reciprocal & Individual & Individual & Survey \\
\hline $\begin{array}{l}\text { Pearce \& Gregersen, } 1991 \\
\text { - } \quad \text { The way I perform my job has a significant impact on others } \\
\text { - My own performance is dependent on receiving accurate } \\
\text { information from others }\end{array}$ & Reciprocal & Individual & Individual & Survey \\
\hline $\begin{array}{l}\text { Campion, Medsker, \& Higgs, } 1993 \\
\text { - I cannot accomplish my tasks without information or materials } \\
\text { from other members of my team } \\
\text { - Other members of my team depend on me for information or } \\
\text { materials needed to perform their tasks }\end{array}$ & Reciprocal & Mix & Mix & Survey \\
\hline $\begin{array}{l}\text { Ashworth, } 2007 \\
\text { - I have to obtain information and advice from others on my team } \\
\text { to complete my work } \\
\text { - I have to work closely with others on my team to do my work } \\
\text { properly }\end{array}$ & Mix & Individual & Individual & Survey \\
\hline Ariel, 2000 & Mix & Team & Team & Survey \\
\hline
\end{tabular}


- $\quad$ To what degree do team members need to work closely together

- $\quad$ To what degree do team members need to coordinate their work efforts

Liden, Wayne, \& Bradway, 1997

- $\quad$ Group members frequently must coordinate their efforts with each other

- $\quad$ The way individual members perform their jobs has significant impact upon others in the group

Mohr, 1971

- $\quad$ Mine is pretty much a one-person job; there is little need for checking or working with others

Pennings, 1975

- $\quad$ Dependent on others for advice and other decisional inputs

Lee, Shin, \& Ki, 2018

- I cannot accomplish my tasks without information or materials from other members of my team

- Within my team, jobs performed by team members are related to one another

Wageman \& Gordon, 2005

- We worked as a team - not a collection of individuals with their own tasks to perform

- $\quad$ My work was not done until everyone had done his or her part Zhang, Hempel, \& Tjosvold, 2007

- $\quad$ The goals of team members go together

- When our team members work together, they usually have common goals

Campion, Medsker, \& Higgs, 1993 (A)

- My work goals come directly from the goals of my team

- My work activities for a given day are determined by my team's goals for that day

Campion, Medsker, \& Higgs, 1993 (B)

\begin{tabular}{|c|c|c|c|}
\hline Mix & Team & Team & Survey \\
\hline Mix & Individual & Individual & Survey \\
\hline Mix & Individual & Individual & Survey \\
\hline Mix & Mix & Mix & Survey \\
\hline Mix & Mix & Mix & Survey \\
\hline Goal & Team & Team & Survey \\
\hline Goal & Individual & Individual & Survey \\
\hline Reward & Individual & Individual & Survey \\
\hline
\end{tabular}


- $\quad$ Many rewards from my job are determined in large part by my contributions as a team member

- $\quad$ My performance evaluation is strongly influenced by how well my team performs

De Dreu, \& West, 2001

- When one or more team members excel in their work, I benefit from that

Ashworth, 2007

- $\quad$ Members of our team are informed about the goals we should attain as a unit

- Members of our team receive feedback on the basis of our collective performance

Janssen, Vliert, \& Veenstra, 1999

- Benefits for one team member involved benefits for others

- $\quad$ Gain for one team member meant gain for others

Van Der Vegt, Enmans, \& Van De Vliert, 2000

- Group members are informed about the goals they should attain as a group

- Group members receive feedback on the basis of their collective performance

O’Brien, 1968 - Intertask Coordination

Wood, 1986 - Coordinative Complexity Oeser \& O’Brien, 1967 - Task x Task Matrix

- Purpose: index the extent of precedence relationships among tasks

O’Brien, 1968 - Interposition Collaboration

Oeser \& Harary, 1962, 1964 - Person x Task Matrix

- $\quad$ Purpose: index the extent to which people work jointly on tasks Lenox, Rockart, \& Lewin, 2007 - NK Model of Interdependence

- $\quad$ Purpose: index the increasing number of potential results as tasks become dependent on one another

\begin{tabular}{|c|c|c|c} 
& & & \\
Reward & Individual & Individual & Survey \\
\hline Mix & Team & Team & Survey \\
\hline Mix & Team & Team & Survey \\
\hline Mix & Team & Team & Survey \\
\hline Task & Either & Either & Observation \\
\hline Task & Either & Either & Observation \\
\hline & & Either & Observation \\
\hline & & & \\
\hline
\end{tabular}


Cataldo, Roberts, \& Herbsleb, 2009 - Syntactic Dependency

- Purpose: index the number of instances where a script references code from another script

Cataldo, Roberts, \& Herbsleb, 2009 - Workflow Dependency - Purpose: index the degree-centrality of the most central individual that works on a script

- Purpose: index the extent to which a file requires other files to be modified during the same commit

Victor \& Blackburn, 1987 - Index of Dependence

- Purpose: index the extent to which rewards are determined by other player's actions (tasks) rather than one's own

Victor \& Blackburn, 1987 - Index of Correspondence

- Purpose: index the extent to which, across the team, rewards determined by an individual's own actions (tasks) are aligned with rewards determined by other's actions (tasks)

\begin{tabular}{l|l|l|l|l} 
& Task & Either & Either & Observation \\
files to & Task & Either & Either & Observation \\
ined by & Outcome & Individual & Individual & Observation \\
wards & Outcome & Team & Team & Observation \\
& & & & \\
& & & & \\
& & & & \\
\end{tabular}


Table 2. Example of raw data from a self-construal scale given to members of two separate teams.

\begin{tabular}{ccc}
\hline Participant ID & Team ID & Self-Construal (1-5) \\
\hline $\mathrm{u} 1$ & team1 & 3 \\
$\mathrm{u} 2$ & team1 & 5 \\
$\mathrm{u} 3$ & team1 & 5 \\
$\mathrm{u} 4$ & team1 & 5 \\
$\mathrm{u} 5$ & & 2 \\
$\mathrm{u} 6$ & team2 & 1 \\
$\mathrm{u} 7$ & team2 & 1 \\
$\mathrm{u} 8$ & team2 & \\
\hline \hline
\end{tabular}


Table 3. Example of SDI scores from the prepared self-construal dataset.

\begin{tabular}{|c|c|c|}
\hline source & team & SDI \\
\hline $\mathrm{u} 1$ & team1 & 0.50 \\
\hline $\mathrm{u} 2$ & team1 & 0.75 \\
\hline u3 & team1 & 1.00 \\
\hline $\mathrm{u} 4$ & team1 & 1.00 \\
\hline team1 & team1 & 0.81 \\
\hline u5 & team2 & 0.25 \\
\hline u6 & team 2 & 0.00 \\
\hline u7 & team2 & 0.00 \\
\hline u8 & team 2 & 0.25 \\
\hline u9 & team2 & 0.00 \\
\hline team 2 & team2 & 0.10 \\
\hline
\end{tabular}

Note: the unit representing the team has an SDI score identical to the aggregated mean SDI score. See appendix A for detailed code for these functions and example raw data. 
Table 4: Example of helping behavior data prepared for SDI function.

\begin{tabular}{|c|c|c|c|}
\hline source & target & teamId & numHelp (0-30) \\
\hline u1 & $\mathrm{u} 2$ & team 1 & 30 \\
\hline $\mathrm{u} 1$ & u3 & team 1 & 2 \\
\hline $\mathrm{u} 1$ & $\mathrm{u} 4$ & team1 & 15 \\
\hline $\mathrm{u} 2$ & u1 & team 1 & 3 \\
\hline $\mathrm{u} 2$ & u3 & team 1 & 12 \\
\hline $\mathrm{u} 2$ & $\mathrm{u} 4$ & team 1 & 4 \\
\hline u3 & $\mathrm{u} 1$ & team 1 & 27 \\
\hline u3 & $\mathrm{u} 2$ & team1 & 3 \\
\hline u3 & $\mathrm{u} 4$ & team 1 & 22 \\
\hline $\mathrm{u} 4$ & u1 & team1 & 5 \\
\hline $\mathrm{u} 4$ & $\mathrm{u} 2$ & team1 & 2 \\
\hline $\mathrm{u} 4$ & u3 & team1 & 25 \\
\hline u5 & u6 & team2 & 1 \\
\hline u5 & u7 & team2 & 7 \\
\hline u5 & $\mathrm{u} 8$ & team 2 & 14 \\
\hline u5 & u9 & team2 & 1 \\
\hline
\end{tabular}




\begin{tabular}{|c|c|c|c|}
\hline u6 & $\mathrm{u} 7$ & team 2 & 16 \\
\hline u6 & $\mathrm{u} 8$ & team2 & 6 \\
\hline u6 & u9 & team 2 & 26 \\
\hline u7 & u5 & team 2 & 1 \\
\hline $\mathrm{u} 7$ & u8 & team 2 & 21 \\
\hline u8 & u9 & team2 & 3 \\
\hline u8 & u6 & team 2 & 1 \\
\hline u9 & u8 & team 2 & 11 \\
\hline
\end{tabular}


Table 6. Example of SDI scores from the helping behavior dataset.

\begin{tabular}{|c|c|c|c|}
\hline source & team & $\mathrm{SDI}_{\text {in }}$ (received) & $\mathrm{SDI}_{\text {out }}$ (initiated) \\
\hline u1 & team1 & 0.39 & 0.52 \\
\hline u2 & team1 & 0.39 & 0.21 \\
\hline u3 & team1 & 0.43 & 0.58 \\
\hline u4 & team1 & 0.46 & 0.36 \\
\hline Mean team1 & team1 & 0.42 & 0.42 \\
\hline u5 & team2 & 0.01 & 0.19 \\
\hline u6 & team2 & 0.02 & 0.40 \\
\hline u7 & team2 & 0.19 & 0.18 \\
\hline u8 & team2 & 0.43 & 0.03 \\
\hline u9 & team2 & 0.25 & 0.09 \\
\hline Mean team 2 & Team2 & 0.18 & 0.18 \\
\hline
\end{tabular}


Figure 1. Example network configurations of Oetzel's (2003) social interdependence study.

\section{Team 1}

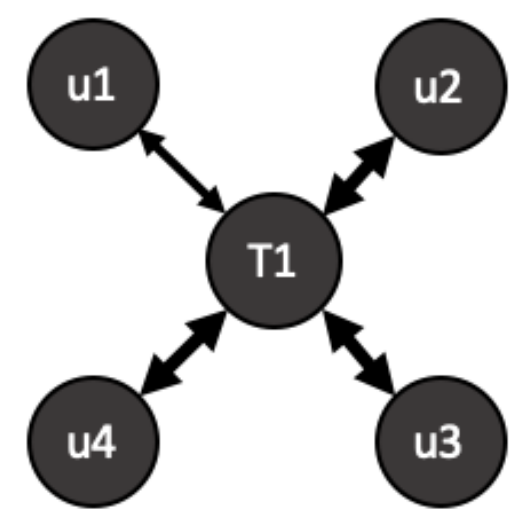

Team 2

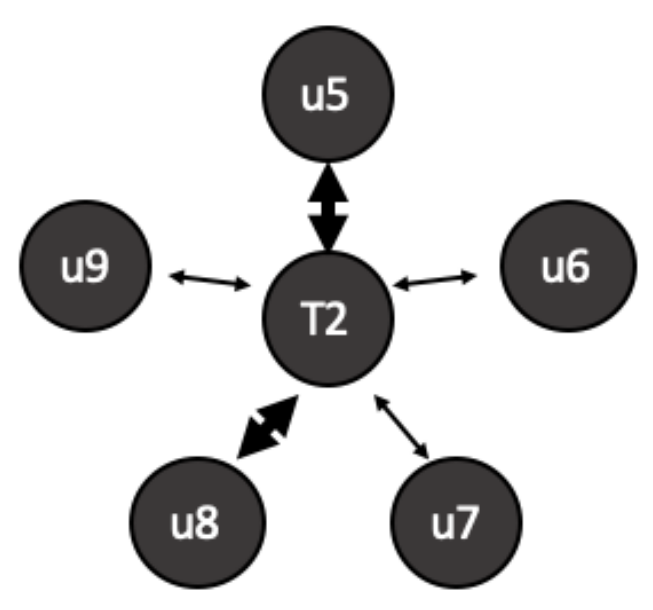


Figure 2. Example network configurations of Barnes, et al. (2003) task interdependence study.
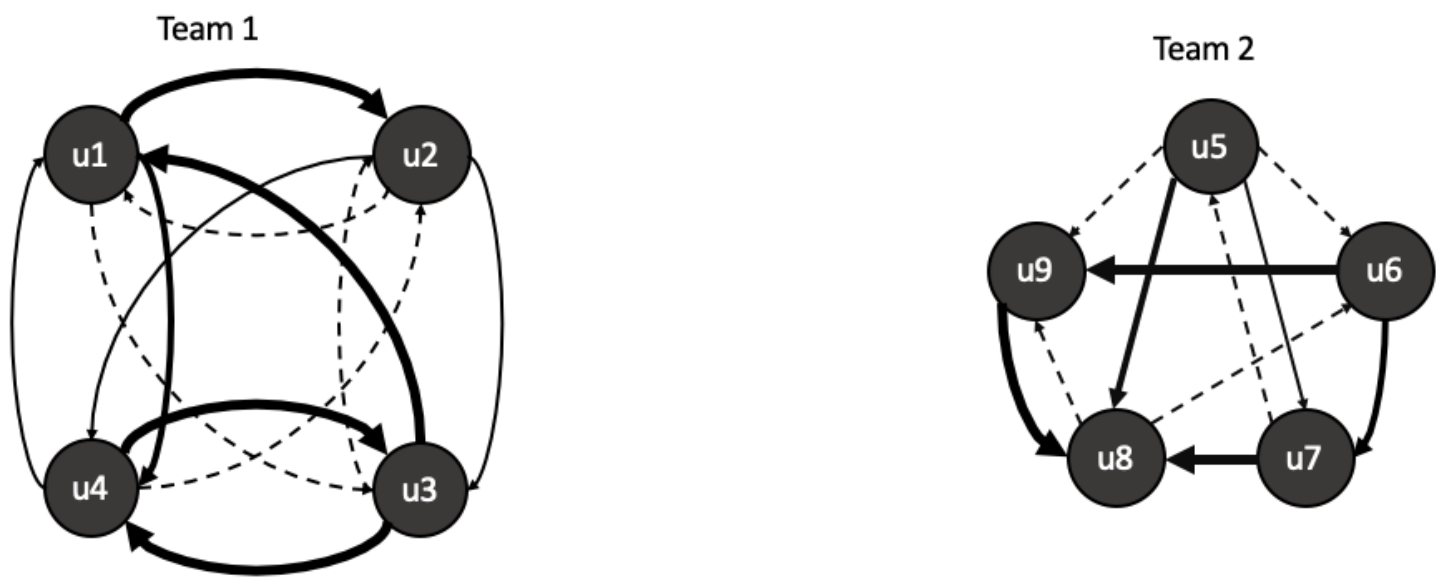

Note. Arrow thickness indicates the strength of a given dependency relationship. Dashed lines indicate dependency relationships that are negligible (i.e. weights less than 0.1). 


\section{Appendix A: R Code Function Declarations}

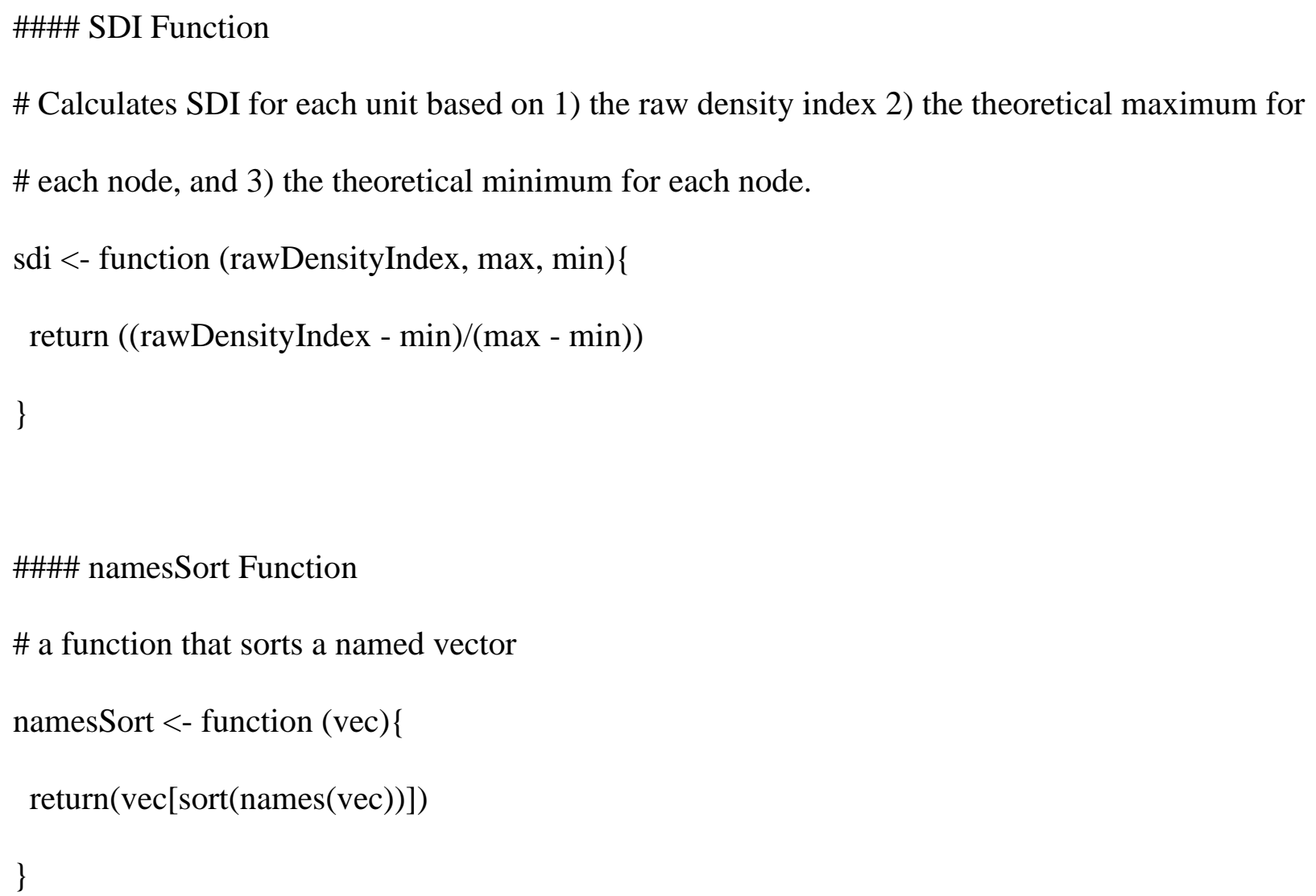


Appendix B: R script examples

library(igraph)

\#\#\#\# Scripts for example 1

\# Step 1. Read in data

rawSelfConstrualData = data.frame( target = c('team1','team1','team1','team1','team2','team2','team2','team2','team2'), teamId = c('team1','team1','team1','team1','team2','team2','team2','team2','team2'), weight $=\mathrm{c}(3,4,5,5,2,1,1,2,1))$

\# Step 2. create graph object from data

scDependencyNetwork = graph.data.frame $($ rawSelfConstrualData, directed $=$ TRUE $)$

\# Step 3. get raw dependency score.

\# Here I we use the strength function to get a

\# weighted degree-centrality score

RDI = strength $($ scDependencyNetwork, mode $=$ "all")

\# Step 4. Set theoretical maximum and minimum scores

RDI_Max = 5*setNames(c(1,1,1,1, 1,1,1,1,1,4,5), c('u1', 'u2', 'u3', 'u4', 'u5', 'u6', 'u7', 'u8', 'u9', 'team1','team2'))

RDI_Min = setNames(c(rep(1,9),4,5), c('u1', 'u2', 'u3', 'u4', 'u5', 'u6', 'u7', 'u8', 'u9', 'team1','team2')) 
\# Step 5. Calculate SDI scores

SDI = sdi(namesSort(RDI),namesSort(RDI_Max), namesSort(RDI_Min))

\#\#\# Scripts for example 2

helpingData = data.frame( source = c('u1', 'u1', 'u1', 'u2', 'u2', 'u2','u3', 'u3', 'u3', 'u4', 'u4', 'u4', 'u5', 'u5', 'u5', 'u5', 'u6', 'u6', 'u6', 'u7', 'u7', 'u8', 'u8', 'u9'), target = c('u2', 'u3', 'u4', 'u1', 'u3', 'u4','u1', 'u2', 'u4', 'u1', 'u2', 'u3', 'u6', 'u7', 'u8', 'u9', 'u7', 'u8', 'u9', 'u5', 'u8', 'u9', 'u6', 'u8'), teamId = c('team1', 'team1', 'team1', 'team1', 'team1', 'team1', 'team1', 'team1', 'team1', 'team1', 'team1', 'team1', 'team2', 'team2', 'team2', 'team2', 'team2', 'team2', 'team2', 'team2', 'team2', 'team2', 'team2', 'team2' ), weight $=c(30,2,15,3,12,4,27,3,22,5,2,25,1,7,14,1,16,6,26,1,21,3,1,11))$

\# Step 2. create graph object from data helpingDependencyNetwork $=$ graph.data.frame $($ helpingData, directed $=$ TRUE $)$

\# Step 3. get raw dependency scores.

\# In this case we use the strength function to get a weighted \# index of in-degree and out-degree centrality RDI_in = strength $($ helpingDependencyNetwork, mode = "in") RDI_out = strength(helpingDependencyNetwork, mode = "out")

\# Step 4. Set theoretical maximum and minimum scores 
\# note that these extreme values are the same for both in and out degree

RDI_Max = 30*setNames(c(rep(3,4),rep(4,5)), c('u1', 'u2', 'u3', 'u4', 'u5', 'u6', 'u7', 'u8', 'u9'))

RDI_Min $=\operatorname{setNames}(\mathrm{c}(\operatorname{rep}(0,9)), \mathrm{c}($ 'u1', 'u2', 'u3', 'u4', 'u5', 'u6', 'u7', 'u8', 'u9'))

\# Step 5. Calculate SDI scores

SDI_in = sdi(namesSort(RDI_in),namesSort(RDI_Max), namesSort(RDI_Min))

SDI_out =sdi(namesSort(RDI_out),namesSort(RDI_Max $)$, namesSort(RDI_Min)) 